Portland State University

PDXScholar

\title{
Contingencies Governing the Production of Fricatives, Affricates, and Liquids in Babbling
}

\author{
Christina E. Gildersleeve-Neumann \\ Portland State University, cegn@pdx.edu \\ Barbara L. Davis \\ University of Texas at Austin \\ Peter F. MacNeilage \\ University of Texas at Austin
}

Follow this and additional works at: https://pdxscholar.library.pdx.edu/sphr_fac

Part of the Psycholinguistics and Neurolinguistics Commons, and the Speech and Hearing Science Commons

Let us know how access to this document benefits you.

\section{Citation Details}

Gildersleeve-Neumann, C. E., Davis, B. L., \& MacNeilage, P. F. (2000). Contingencies Governing the Production of Fricatives, Affricates, and Liquids in Babbling. Applied Psycholinguistics, 21(3), 341-363. doi:10.1017/S0142716400003039

This Article is brought to you for free and open access. It has been accepted for inclusion in Speech and Hearing Sciences Faculty Publications and Presentations by an authorized administrator of PDXScholar. Please contact us if we can make this document more accessible: pdxscholar@pdx.edu. 
Applied Psycholinguistics 21 (2000), 341-363

Printed in the United States of America

\title{
Contingencies governing the production of fricatives, affricates, and liquids in babbling
}

\author{
CHRISTINA E. GILDERSLEEVE-NEUMANN, BARBARA L. DAVIS, \\ and PETER F. MACNEILAGE \\ University of Texas, Austin \\ ADDRESS FOR CORRESPONDENCE \\ Christina Gildersleeve-Neumann, Department of Communication Sciences and Disorders, \\ University of Texas, Austin, TX 78712. Email: christina.g.neumann@mail.utexas.edu
}

\begin{abstract}
Studies of early-developing consonants (stops, nasals, and glides) in babbling have shown that most of the variance in consonants and their associated vowels, both within and between syllables, is due to a "frame" produced by mandibular oscillation, with very little active contribution from intrasyllabic or intersyllabic tongue movements. In a study of four babbling infants, the prediction that this apparently basic "frame dominance" would also apply to late-developing consonants (fricatives, affricates, and liquids) was tested. With minor exceptions, confirming evidence for both the predicted intrasyllabic and intersyllabic patterns was obtained. Results provide further evidence for the frame dominance conception, but suggest that the early rarity of late-developing consonants may be primarily a result of intrasegmental production difficulty.
\end{abstract}

Fricatives, affricates, and liquids are relatively rare in babbling and early speech and have been subject to little systematic study. A complete characterization of babbling requires more attention to these sounds. Moreover, as a number of the sounds in these categories are subject to pronunciation difficulties in developing children, it seems desirable, from a clinical standpoint, to understand more fully the circumstances governing their production. This article presents intensive case studies of the production of these late-developing consonants (LDCs) in the babbling of four infants in an English-speaking environment. These consonants are compared with early-developing consonants (EDCs), which are stops, nasals, and glides.

\section{The low frequency of occurrence of LDCs in babbling}

The relative rarity of fricatives, affricates, and liquids in babbling of infants in English-speaking environments is well documented. The most comprehensive source of information available is Locke's (1983) summary of three studies involving a total of 131 American infants. No instance of any of these sound

(c) 2000 Cambridge University Press 0142-7164/00 $\$ 9.50$ 
types occurred in the top ten consonants in these studies, as determined by median percentage of occurrence. None of the individual sounds had a median percentage of occurrence higher than 1.0 (Stoel-Gammon \& Dunn, 1985). And yet these consonants account for almost half of all consonantal occurrences in words in English (Kent \& Read, 1992).

This rarity of LDCs in babbling may be universal. In a survey of studies of babbling in fifteen language environments, Locke (1983) found that none of the individual LDCs that occur as phonemes in English (fricatives: /f/, /v/, / $\theta /$, /ð/, /s/, /z/, / / /, /3/; affricates: /t $\mathrm{J} /, / \mathrm{d} 3 /$; liquids: /l/, / $/$ /) were in the top ten consonants in terms of the frequency with which they occurred in a particular language environment. None of the individual sounds were observed in more than five of the fifteen languages. These estimates changed very little when Locke corrected for the presence of particular sounds in the adult language.

Almost no attention has been given to the question of why these sounds are rare in babbling when at least some of them occur very frequently in the languages of the world (Maddieson, 1984) and are very frequent in input to infants in an English-speaking environment (Kent \& Read, 1992). Either perceptual- or production-based causes could be involved. There are reasons to suspect that perceptual factors do not play an important role in limiting the output of these sounds. According to Kuhl (1987), "The number and diversity of contrasts that have been successfully discriminated by infants has led to the conclusion that infants under the age of 4 months can discriminate many, perhaps all, of the phonetic distinctions relevant in English" (p. 311). By the age of 10 months, infants are already more efficient in discrimination tasks involving the phonetic categories that are used in their own language (Werker \& Tees, 1984). In addition, the high frequency with which infants who cannot produce a particular sound substitute another sound with a comparable place of articulation shows that they at least have a perceptual representation relevant to the place of articulation of the sound in question.

In contrast to perceptual factors, production factors can be readily implicated in the low frequencies of LDCs in babbling. In the case of fricatives, two requirements are the formation of an aperture within a small range of error relative to size and the establishment of an air pressure drop across this constriction which is also range-limited. For affricates, it is necessary to produce a total occlusion as in a stop and then a narrow constriction as in a fricative, both events being briefer than in singleton stops and fricatives. Liquid production requires a relatively unusual tongue configuration. For /1/ the tongue must simultaneously produce an occlusion in the midline and an aperture on one or both sides of the midline to produce a lateral airstream. For $/ \mathrm{x} /$ the tongue must be either in a retroflex configuration with the tongue tip curled backward or bunched simultaneously in regions placed one-third to two-thirds of the way along the vocal tract in order to produce the requisite acoustic effect. No objective index of articulatory difficulty exists for LDCs. However, the absence of obvious perceptual explanations for their rarity and the fact that at least some of these sounds (especially /s/ and /ð/) are often not produced correctly until late in speech acquisition (Sander, 1972) suggest an explanation involving motor constraints. 
Gildersleeve-Neumann et al.: Late-developing consonants in babbling

\section{The frame dominance perspective on babbling}

A perspective for the study of LDCs can be gained by considering babbling from the standpoint of serial organization. According to the "frame dominance" concept (Davis \& MacNeilage, 1995), the serial organization of babbling is primarily determined by a "frame" consisting of rhythmic mandibular oscillation. The proposed dominance of the frame is considered to result from the virtual absence of an active role of articulators other than the mandible during babbled utterances. Each of these articulators (lips, tongue, soft palate) is considered either to remain in rest position during entire babbling episodes or to assume a nonresting position at the beginning of a babbling episode and to retain this position throughout. As a result of this pattern, serial interdependence is a hallmark of babbling episodes. This interdependence appears in its most obvious form in the obligatory concurrence of vowel and consonant. Beyond that, the static positioning of articulators other than the mandible results in aspects of vocal tract configuration remaining similar across frame cycles (e.g., either a resting or a fronted position). It is convenient to discuss the two types of interdependency separately. First, short-term or intracyclical interdependencies between adjacent consonants and vowels are referred to as intrasyllabic for expository convenience, although there is no assumption that the syllable is a separable control unit. Most work has been on the consonants and vowels that follow them (CV co-occurrences). Second, regarding long-term or intersyllabic interdependencies, the basic question is, how similar is a following syllable to the preceding one? We review the evidence pertaining to these types of interdependency in turn and consider the implications of the evidence for LDCs.

\section{Intrasyllabic CV co-occurrence patterns}

A number of earlier studies have suggested that babbling and early speech might be subject to specific intrasyllabic interdependencies. Some studies suggested that infants mispronounce words with a labial consonant-front vowel sequence by producing an alveolar (front) consonant instead, suggesting a tongue-front position constraint (Braine, 1974; Fudge, 1969; Jakobson, 1968/1941; StoelGammon, 1983). Hodge's (1989) acoustic evidence suggested that apical articulation in babbling is performed with passive movement of the tongue cooccurring with active movement of the mandible. Fudge (1969) also reported tendencies in one infant to produce bilabial consonants with back rounded vowels.

More recently the question of intrasyllabic interdependencies has been systematically investigated in a series of quantitative case studies of 14 subjects in which the database for a single subject always exceeded 1,000 syllables. Davis, MacNeilage, and their colleagues (Davis \& MacNeilage, 1994; MacNeilage \& Davis, 1996; Zlatic, MacNeilage, Matyear, \& Davis, 1997) accumulated a large body of evidence for three types of what can be called CV co-occurrence constraints. These were initially predicted to occur in babbling following an earlier study of a 14- to 20-month-old infant (Davis \& MacNeilage, 1990). In the study of early words and concurrent babbling (Davis \& MacNeilage, 1990), alveolar consonants co-occurred with front vowels, velar consonants co-occurred with 
back vowels, and labial consonants co-occurred with central vowels. In the absence of any obvious reason for why these co-occurrence patterns would only develop after speech began, it was hypothesized that these patterns would also be present in babbling. This hypothesis was tested for stops, nasals, and glides in three studies (Davis \& MacNeilage, 1994 [one infant]; Zlatic et al., 1997 [two infants]; Davis \& MacNeilage, 1995 [six infants]). Except for one null result, the 24 possible tests of the three hypotheses (three infants did not have enough velar consonants to evaluate their co-occurrence with back vowels) all showed the predicted patterns, most often at statistically significant levels. Subsequent studies of first word production and concurrent babbling (analyzed separately) of five infants by Davis and MacNeilage (1995) and of five infants by MacNeilage and Davis (1996) have resulted in 29 trends consistent with the hypotheses in concurrent babbling, with one exception, and 26 confirmations in first words, with four exceptions, all involving velars and back vowels. Trends in first words tended to be less strong than in babbling. Overall, then, 78 out of 84 tests of these CV co-occurrence hypotheses (more or less evenly distributed across prespeech babbling, first words, and babbling concurrent with first words) have resulted in confirmation of the three trends.

A number of other published studies of $\mathrm{CV}$ co-occurrences in babbling and early speech have produced not only many confirmations of these findings, but also counterexamples and null findings (Boysson-Bardies, 1993; Oller \& Steffens, 1993; Tyler \& Langsdale, 1996; Vihman, 1992). These studies have uniformly involved much smaller databases per infant than the studies cited here, sometimes using different vowel classifications and sometimes failing to account for the overall frequencies of both consonantal and vowel categories when computing expected frequencies for the individual CV classes.

The disconfirmations of the findings of Davis, MacNeilage, and colleagues by others raise the issue of whether their almost uniformly positive results may be due to a transcription bias. Subsequent studies, however, suggested that transcription bias was not the reason for the uniformity of the results of this group. First, in a study by Davis, MacNeilage, and Matyear (2000), confirmation levels were as high in the four subjects who were not transcribed by members of the group as in the six subjects who were. Second, an acoustical study showed that, even when transcriptions were counter to the hypothesis (labials with front vowels, coronals with centrals), second formant patterns were significantly in the direction of the predicted trends (i.e., higher second formants) in coronal environments) (Matyear, MacNeilage, \& Davis, 1997).

What explanations can be offered for these co-occurrence patterns? The fact that lingual stops, nasals, and glides tend to co-occur with vowels involving a similar tongue position in the front/back dimension suggests the presence of a basic biomechanical constraint against tongue movements in the front/back dimension in the transition from consonants to vowels. The patterns resulting from these constraints have been called "fronted" and "backed" frames (MacNeilage \& Davis, 1990), implying that most of the variance in CV alternations comes from oscillation of the mandible with the tongue tending towards a static position in the front or back of the mouth. The third type of co-occurrence 
A al.: Late-developing consonants in babbling

Table 1. Relations between observed and expected frequencies of various CV pairings in the Oxford Psycholinguistic Database

\begin{tabular}{|c|c|c|c|c|c|c|c|c|c|c|}
\hline & \multicolumn{10}{|c|}{ Consonants } \\
\hline & \multicolumn{3}{|c|}{ Stops and nasals } & \multicolumn{5}{|c|}{ Fricatives and affricates } & \multicolumn{2}{|c|}{ Liquids } \\
\hline & $\mathrm{p}, \mathrm{b}, \mathrm{m}$ & $\mathrm{t}, \mathrm{d}, \mathrm{n}$ & $\mathrm{k}, \mathrm{g}, \mathrm{\eta}$ & $\mathrm{f}, \mathrm{v}$ & $\theta$, б & $\mathrm{s}, \mathrm{z}$ & $\int, 3$ & $\mathrm{t} \int, \mathrm{d} 3$ & 1 & $\mathrm{I}$ \\
\hline \multicolumn{11}{|l|}{ Vowels } \\
\hline Front & 1.00 & 1.17 & .60 & .94 & 1.03 & 1.12 & .35 & 1.13 & 1.13 & 1.25 \\
\hline Central & 1.02 & .97 & 1.35 & 1.10 & 1.05 & 1.03 & 2.12 & .90 & .88 & .78 \\
\hline Back & 1.02 & .51 & 1.50 & .92 & .78 & .45 & .28 & .81 & .86 & .71 \\
\hline
\end{tabular}

constraint - labials with central vowels - is considered to arise from "pure frames"; the entire pattern may typically be produced by mandibular oscillation alone (i.e., with mandibular elevation the lips touch or approximate each other, and with mandibular depression the resting tongue position gives rise to the acoustical pattern of a central vowel). Munhall and Jones (1998) reported an absence of independent lip activity in the production of labial consonants in the babbling of one infant. Hodge (1989) and Nittrouer (1993) also presented evidence for a bigger role of the mandible than of the tongue early in speech acquisition.

Understanding of these patterns may be enhanced by considering how they relate to CV co-occurrence patterns in adult speech. In a study of stops and nasals in 12,630 words derived from dictionary counts of ten languages, the labial consonant-central vowel co-occurrence was observed in seven languages, the coronal consonant-front vowel co-occurrence in seven languages, and the dorsal consonant-back vowel co-occurrence in eight languages (MacNeilage, Davis, Kinney, \& Matyear, 1999). The average ratios of observed to expected co-occurrence were: labial-central, 1.10; coronal-front, 1.18; dorsal-back, 1.27. (These expected frequencies were computed on the basis of the total number of occurrences of the consonant category and the vowel category forming the $\mathrm{CV}$ pair. For example, if the total number of consonants in the category was .2 of all consonants and the total number of vowels in the category was .3, then the expected frequency for the cell would be $.2 \times .3=.06$ of the total corpus.)

The presence of these co-occurrence constraints in infants and in diverse languages suggests that they play an extremely fundamental role in language patterning. While they have so far been investigated primarily in EDCs, a prediction motivating the present study is that they are also characteristic of LDCs. The strength of this expectation is increased by consideration of a summary of $\mathrm{CV}$ co-occurrence constraints involving all consonants in the English language (Table 1). This table is derived from a count of all CV sequences in the Oxford Psycholinguistic Database (Quinlan, 1992) in words ranging in size from 2 to 19 sounds. Every instance in which a consonant was followed by a vowel was 
analyzed. The total number of pairs was 81,409. The numbers are ratios of observed frequencies to expected frequencies.

The CV co-occurrence constraints observed in infants are present in almost all categories. In all coronal subcategories except $/ \mathrm{S} /-/ 3 /$, the observed number of consonants in front vowel environments exceeds expectation. The lowest frequency vowel category, relative to expectation for all coronal categories, was the back vowel category. In contrast, the highest frequency of vowels, relative to expectation for dorsal consonants, was for back vowels, and the lowest frequency was for front vowels. In the labial category, the highest vowel frequencies, relative to expectation for fricatives, were for central vowels, but there was no trend for stops and nasals. This result may be due to a tendency for coronal consonants to follow labials in languages. It was found that in nine of ten languages, including English, initial labial stops and nasals tend to be followed more than twice as often on the average by coronal consonants (which are associated with front vowels) than by another labial consonant (MacNeilage et al., 1999). If labials followed intervocalically by another labial are considered separately in this corpus, then a strong tendency for the intervening vowel to be a central vowel is observed. The tendency in English of the LDCs (with the exception of $/ \mathrm{J} /-/ 3 /$ ) to exhibit the $\mathrm{CV}$ co-occurrence constraints shown for stops and nasals in infants (i.e., labials with central vowels and coronals with front vowels) suggests that we should find similar co-occurrence constraints on LDCs in infants.

Nonrandom patterns of co-occurrence constraints provide one indication of intracyclical interdependence in babbling and early speech. Another source of support for this conclusion is found in acoustic studies of coarticulation. Two studies addressed the babbling stage (Sussman, Duder, Dalston, \& Cacciatore, 1999; Sussman, Minifie, Buder, Stoel-Gammon, \& Smith, 1996). The latter study involved coarticulation between $/ \mathrm{b} / \mathrm{/} / \mathrm{d} /$, and $/ \mathrm{g} /$ and the following vowels in one infant in the present study; correlations indicative of coarticulation were found between the second formant at consonant release and the second formant of the following vowel. Consistent with the implications of transcription studies, the authors inferred that "inherent motor constraints [were] already in operation in prespeech babbling."

\section{Intersyllabic patterns}

Although many babbled utterances are monosyllabic, it is more typical for an infant to produce strings of two or more syllables. Until recently, it had been proposed that a babbling infant went through two successive stages of multisyllabic babbling (Oller, 1980; Stark, 1980). The first was a stage of reduplicative babbling in which the same syllable was repeated throughout the babbling episode. From the frame dominance perspective (Davis \& MacNeilage, 1995), this pattern is regarded as frame reiteration - the mandible cycles repeatedly with no change in any other articulator. The second stage was labeled "variegated babbling," in that consonants, vowels, or both could be different. However, recent studies have shown that variegated babbling is not uncommon in early 
babbling (Davis \& MacNeilage, 1995; Mitchell \& Kent, 1990; Smith, BrownSweeney, \& Stoel-Gammon, 1989). Thus, there may not be any clear progression in occurrence of variegation across the babbling period. In Davis and MacNeilage (1995), an analysis of every instance in which a CV syllable was followed by another syllable revealed that the median frequency with which the second syllable was the same as the first was about $50 \%$ in both the first and second half of babbling. This percentage, which was well above that expected on the basis of the overall frequencies in the corpus of the consonants and vowels participating in the reduplications, indicates that reduplication was the dominant intersyllabic form in the corpus. Individual analyses of EDCs showed that the main consonantal forms $(/ \mathrm{b} /, / \mathrm{d} /, / \mathrm{m} /$, and $/ \mathrm{n} /)$ were reduplicated over $75 \%$ of the time in these syllables.

What variables are responsible when variegated babbling episodes occur instead of reduplicated episodes? As most intracyclical variation involves the frame alone and as reiteration of the frame is the main mode of multicyclical babbling, it would seem likely that intercyclical variation is also primarily attributed to the frame. The results obtained so far are consistent with the earlier prediction (Davis \& MacNeilage, 1995) that most changes take place in what could be called the "vertical" dimension of articulator height rather than in "horizontal" variegation, which involves changes in the front/back dimension of tongue movement. Mitchell and Kent (1990) and Davis and MacNeilage (1995) found that most consonantal changes were in manner of articulation, which primarily involves the amount of mouth opening. Redford, MacNeilage, and Davis (1997) reported that manner variegation exceeded place variegation $(46.5 \%$ to $24.3 \%$ ) in a study of 721 absolute final consonants and the consonants preceding them intervocalically in six infants (approximately half of the samples were CVC utterances, and the other half terminated in a CVC sequence). In contrast to these studies, Smith et al. (1989) found more changes in place of articulation than in manner, though they did not include glides in their analysis, thus eliminating what was the main source of manner variegation in the Davis and MacNeilage (1995) study. In the only study that also involved vowels, most vowel changes were found to involve vowel height rather than the front/back dimension. Davis and MacNeilage (1995) attributed this predominance of vertical over horizontal variation to a single source, termed "frame modulation," where variation in the amplitude of one or more phases of mandibular elevation or depression during an utterance was the main source of variegation in babbling. Similar effects were also found in early speech (MacNeilage \& Davis, 1996). The frame modulation hypothesis leads to the prediction that, when LDCs participate in variegated babbling, place of articulation of a consonant will tend to be the same as the consonant separated from it by an adjacent vowel, as place variegation involves horizontal variegation, which appears to be relatively rare.

No studies have examined participation of LDCs in variegated babbling. However, as in the case of intracyclical interdependencies, it is predicted that LDCs will be subject to the same influences as EDCs. Consequently, vowels in LDC contexts should vary more often in height than in the front/back dimension, and consonants should vary more often in manner than in place intercyclically. 
Gildersleeve-Neumann et al.: Late-developing consonants in babbling

\section{Position-in-utterance effects}

In addition to the two types of contextual effect addressed by the frame dominance concept (intrasyllabic and intersyllabic effects), there is another set of contextual effects which involves a babbled utterance as a whole. There are different contextual contingencies, depending on whether an utterance is beginning, continuing, or ending. The main utterance-position constraint in babbling and early speech is the strong tendency for utterances to begin with a consonant and end with a vowel (Vihman, 1996). However, when final consonants do occur, fricatives are more frequent relative to other consonants in this position than elsewhere in utterances. Examining the canonical babbling of nine infants from 6 to 8 months of age, Oller, Wieman, Doyle, and Ross (1976) found that, while initial stops outnumbered initial fricatives and affricates, final fricatives outnumbered final stops. Liquid productions only occurred prevocalically. There seems to be no consensus regarding utterance-position effects on liquids, perhaps due to their very low frequencies of occurrence. Kent and Bauer (1985) analyzed the canonical babbling of five infants at 13 months. They found that fricatives outnumbered stops in VC environments and stops outnumbered fricatives in $\mathrm{CV}$ environments. Liquids were not reported in initial position and comprised only $2 \%$ of the final consonant inventory, occurring most frequently intervocalically. Cross-linguistic analysis of phonotactic distribution by Oller and Eilers (1982) showed that eight infants exposed to English and eight infants exposed to Spanish between 11 and 14 months of age produced a higher proportion of fricatives and affricates word finally than word initially. Redford et al. (1997) found that fricatives were produced significantly more often in final position (24\%) than in prefinal position (7\%). Stoel-Gammon and Dunn (1985), in a study of 34 infants in an English-speaking environment, did not find a consistent positional pattern for emergence of fricatives or liquids.

Redford et al. (1977) also reported relatively more voiceless consonants in final position (see also Menn, 1983, regarding early words) and more nasals in final position. These results, together with the final fricative predominance noted in other studies and reports of a terminal reduction in fundamental frequency (Kent \& Murray, 1982; Levitt \& Wang, 1991) and intensity (Davis, MacNeilage, Matyear, \& Powell, in press) in babbling episodes, led Redford et al. (1997) to suggest that these trends may be the result of a tendency toward an utterance-terminal decrease in energy delivered to the speech apparatus. Based on these results, the higher relative frequencies of fricatives in final position would not be specific to fricative production but would be part of general utterance-level physiological effects. In addition to considering intracyclical and intercyclical contextual effects on LDCs, position-in-utterance effects for LDCs are also investigated.

\section{Aims of the study}

The first aim of this study is to determine the frequencies of occurrences and the overall distribution of LDCs in the babbled utterances of four normally developing infants. Then the question of whether, and in what ways, the occurrence of these sounds is subject to the three classes of constraints is addressed. 
Applied Psycholinguistics 21:3

Gildersleeve-Neumann et al.: Late-developing consonants in babbling

Table 2. Infant characteristics

\begin{tabular}{ccccc}
\hline \hline Subject & Gender & $\begin{array}{c}\text { Age range } \\
\text { (yrs.;mos.) }\end{array}$ & $\begin{array}{c}\text { Number of } \\
\text { sessions }\end{array}$ & $\begin{array}{c}\text { 1st word onset } \\
\text { (yrs.;mos.) }\end{array}$ \\
\hline C & F & $0 ; 7-1 ; 3$ & 26 & $0 ; 11$ \\
N & M & $0 ; 9-1 ; 7$ & 36 & $1 ; 1$ \\
P & M & $0 ; 7-1 ; 6$ & 33 & $1 ; 3$ \\
R & F & $0 ; 7-1 ; 6$ & 36 & $0 ; 11$ \\
\hline \hline
\end{tabular}

1. Intrasyllabic CV co-occurrence patterns. Are the same patterns observed for stops, nasals, and glides observed for LDCs? These patterns are considered to be related to place of articulation, independent of manner of articulation, from the frame dominance perspective. The predictions are that labial fricatives will tend to co-occur with central vowels: coronal fricatives, affricates, and liquids, with the exception of $/ \mathrm{J} /$ and $/ 3 /$, will tend to occur with front vowels, and velar fricatives will tend to occur with back vowels.

2. Intersyllabic patterns. To what extent do LDCs participate in reduplicative versus variegated sequences? Is their participation in variegated utterances similar to the predictions made for EDCs (i.e., the tendency of most consonantal variegation to be in manner of articulation and vocalic variation to be in the height dimension)?

3. Position-in-utterance patterns. What are the relative frequencies of fricatives and the frequency of occurrence of affricates and liquids across utterance position? The tendency of the infants in this study to produce more fricatives in final position has already been documented (Redford et al., 1997; Sussman et al., 1999; Sussman et al., 1996).

\section{METHOD}

The data analyzed for this investigation are from a longitudinal study on early normal speech development. Data collection began with the onset of canonical babbling of four normally developing infants. Table 2 shows gender, chronological ages during data collection, sessions analyzed, and chronological ages at first word onset.

The four infants were selected through an informal search in the community. Prior to participation in the study, normal development was established using the Battelle Developmental Screening Inventory (Guidabaldi, Newborg, Stock, Svinicki, \& Wneck, 1984), as well as parent case history report. Regular contact with parents was established when the infants were 6 months of age. Data collection began when the parents reported the onset of canonical babbling. The infants were seen weekly for one hour in their home environment. Each infant's vocal output was audiotaped and transcribed by an observer present in the environment during data collection. An ATW-20 digital audio recorder was used to 
collect and transcribe the data. An Audiotechnika ATW-1031 remote microphone, clipped to the shoulder of the infant to allow a constant mouth-to-microphone distance, was used for data collection.

Observers were trained in infant transcription prior to the onset of the study. Broad transcription with diacritics for infant speech was employed (Bush et al., 1973). Only comfort state vocalizations were transcribed. No single consonant or vowel segments, vegetative sounds, or vocalizations not determined to be canonical babbling were analyzed. Utterances that were difficult to transcribe due to excessive background noise were excluded. The data analysis in this study only included canonical babbling; no utterances that were determined to be meaningful lexical items were included. Word determinations were made by the original transcriber and the infant's parents, based on context and familiarity.

Data were tabulated for computer analysis using the Logical International Phonetics Program (Oller, 1990). Intertranscriber reliability for LDCs was determined by having four observers transcribe approximately 20 utterances containing EDCs and LDCs from each of the four infants. EDCs were included in the samples to avoid transcriber bias toward the transcription of LDCs. Mean transcriber agreement was $75.9 \%$, with a range from $56.3 \%$ to $86.4 \%$. In the transcription of LDCs, place of articulation tended to be more accurate than manner. Vowels were divided into front, central, and back categories for reliability analysis. Mean transcriber agreement was $73.5 \%$ and ranged from $55 \%$ to $87 \%$.

Data were analyzed for each infant for the entire developmental period. While split-half analysis was conducted, little change over time was noted, and only data for the entire time period are reported.

For analysis of $\mathrm{CV}$ and $\mathrm{CVCV}$ co-occurrences, consonants and vowels were grouped according to place of articulation. The glides [j] and [w] were classified as consonants because, like "true" consonants, they occur during the closing phase of the mouth open/close alternation associated with syllable production from the onset of babbling. Consonants were divided into three groups: labial, coronal, and dorsal. At the labial place, $[\beta, \Phi, \mathrm{v}, \mathrm{f}]$ were analyzed as LDCs. Consonants considered as coronals are those involving articulatory contact of the anterior tongue portion. The coronal LDCs analyzed were $[\delta, \theta, z, s, d z, t s$, $\left.13,3, \int, d_{3}, \mathrm{t} \int, 1, \mathrm{I}, \mathrm{d}, \mathrm{c}, \mathrm{K}\right]$. Dorsal consonants involve articulatory contact of the posterior portion of the tongue. The fricatives $[\mathrm{x}, \mathrm{x}]$ were the dorsal LDCs in this data set. Trills, such as [B, r, R], while present in the data, were extremely rare in CV syllables and therefore were excluded from analysis. [h] and [?] were not included in the analysis as their production does not involve oral cavity adjustments. Vowels were grouped according to the front/back axis of produc-

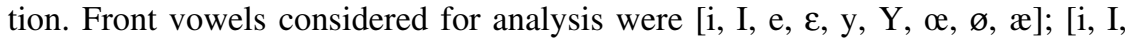
$\mathrm{e}, \varepsilon, æ]$ occurred with most frequency. Analysis of central vowels included $[\dot{i}$, $\left.\sharp, \partial, \Lambda, a, \gamma^{\prime}\right]$, with $[\Lambda, \partial, a]$ occurring most frequently. Analysis of back vowels included [u, $v, \mathrm{u}, \mathrm{o}, \mathrm{\rho}, \mathrm{p}]$; the most frequent back vowels were $[\mathrm{u}, \mathrm{U}, \mathrm{o}, \mathrm{\rho}]$.

Variegation was defined as either a consonant change in place and/or manner or a vowel change in the height and/or front back axis within a disyllable. All syllables analyzed for variegation included at least one LDC. In this study, disyllables containing voiced and unvoiced consonants of the same place and 
manner were considered reduplicated, as were disyllables containing vowels differing only in the tense/lax dimension.

An utterance with $n$ syllables contains $n-1$ two-syllable strings. Each twosyllable string was counted in the analysis. For example, in the utterance [dæsIsI], the first [sI] syllable would be analyzed twice: as the second CV syllable in the variegated \#CVCV string \#[dæsI] and as the first CV syllable in the reduplicated string [SISI]. For the comparison of variegated to reduplicated utterances, the frequency of LDC reduplication was of interest. Therefore, reduplicated CVCV strings included those in which the LDCs did not change, regardless of vowel productions.

\section{RESULTS}

A total of 1,430 LDCs was produced. The Appendix displays frequency and percentage of occurrence for all LDCs for the four infants. If individual results differed substantially from group mean results, both individual results and those for the group are reported.

\section{Inventories}

The four infants produced a total of 38,341 vowel and consonant phones during the period. Subject C produced 13,603; N produced 8,913; P produced 4,726; and $\mathrm{R}$ produced 11,099. Consonants were approximately $50 \%$ (ranging between $48.5 \%$ and $50.4 \%$ ) of the total phones produced by each infant. Of the 18,866 total consonant phones, $7.6 \%$ were LDCs. The mean percentage of EDCs across individual infants in this study was $91.2 \%$, and for LDCs it was $8.8 \%$. Subject $\mathrm{R}$ had the highest number of LDCs (18\%), and $\mathrm{N}$ had the lowest (3\%).

The highest percentages of LDCs were produced in the coronal region. Coronal LDCs accounted for between $75 \%$ and $85 \%$ of all LDCs in individual infants. Dorsal LDCs were extremely low in occurrence; only two infants ( $R$ and P) produced any dorsal LDCs.

Figure 1 shows the frequency of LDCs classified in terms of manner of articulation. Liquids averaged approximately $4 \%$ of the total number of consonants produced by the group. The number of liquids produced by individual infants ranged between $1 \%(\mathrm{~N})$ and $8 \%(\mathrm{P})$ of the infant's total consonant sounds. Fricatives averaged slightly more than $4 \%$ of total consonant sounds produced by the group and ranged between less than $1 \%(\mathrm{C})$ and $11 \%(\mathrm{R})$ of the infant's total consonants. Two infants $(\mathrm{C}$ and $\mathrm{P})$ produced approximately three times as many liquids as fricatives; one infant $(\mathrm{N})$ produced an approximately equal number of fricatives and liquids; and one infant $(\mathrm{R})$ produced approximately twice as many fricatives as liquids. Few affricates were produced by any infant.

\section{Intrasyllabic CV co-occurrence patterns}

The first issue to consider is whether, as in adults, $/ \mathrm{J} /$ and $/ z /$ are counterexamples to the coronal-front vowel co-occurrence pattern, occurring preferentially with central vowels. Only one infant in the study produced more than six CV 
Gildersleeve-Neumann et al.: Late-developing consonants in babbling

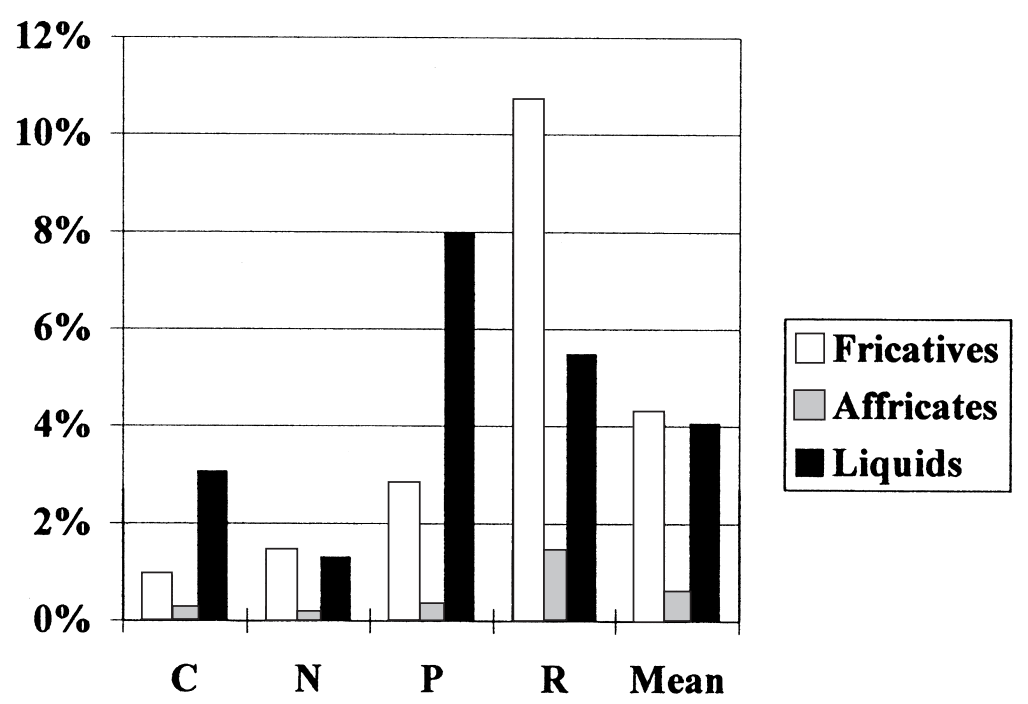

Figure 1. The percentage of each infant's consonant inventory comprised of liquids, fricatives, and affricates and the average percentages of each for the group.

syllables with $/ \int /$ and $/ 3 /$. In this infant, front and central vowels co-occurred with these consonants at levels close to those expected on the basis of the total number of front and central vowels produced.

Figure 2 shows the results in percentages of $\mathrm{CV}$ co-occurrences for labial fricatives, coronal fricatives, affricates, and liquids. Because liquids varied in their pattern of CV co-occurrence from other coronal LDCs for all infants, they were separated from other coronal LDCs for CV co-occurrence analysis. As expected, there was a trend for labial fricatives to co-occur with central vowels and for coronal fricatives to co-occur with front vowels. However, the tendency for liquids to co-occur with central vowels was unexpected.

The overall ratios of observed to expected frequencies for the three classes of consonants and vowels are shown in Table 3. CV co-occurrence patterns were evaluated for each individual subject. Expected frequencies of any particular $\mathrm{CV}$ subset were derived from the overall frequencies of the particular consonant and vowel subclasses in the entire corpus. Chi-square analysis revealed significant associations between contiguous consonants and vowels for eight of the nine possible co-occurrences. One analysis was nonsignificant: CV co-occurrence patterns for P's observed production of liquids matched expected levels. Analyses could not be conducted on three patterns due to low frequency of consonants: coronal fricatives and affricates for $\mathrm{C}$ and $\mathrm{P}$ and labial fricatives for $\mathrm{N}$. The results of the nine chi-square analyses conducted were as follows: labial fricatives $-(2, N=24)=7.86, p<.05$, for $\mathrm{C} ;(2, N=46)=11.74, p<01$, for $\mathrm{P}$; $(2, N=150)=83.4, p<.001$, for R; coronal fricatives and affricates $-(2, N=$ 
Applied Psycholinguistics 21:3

Gildersleeve-Neumann et al.: Late-developing consonants in babbling

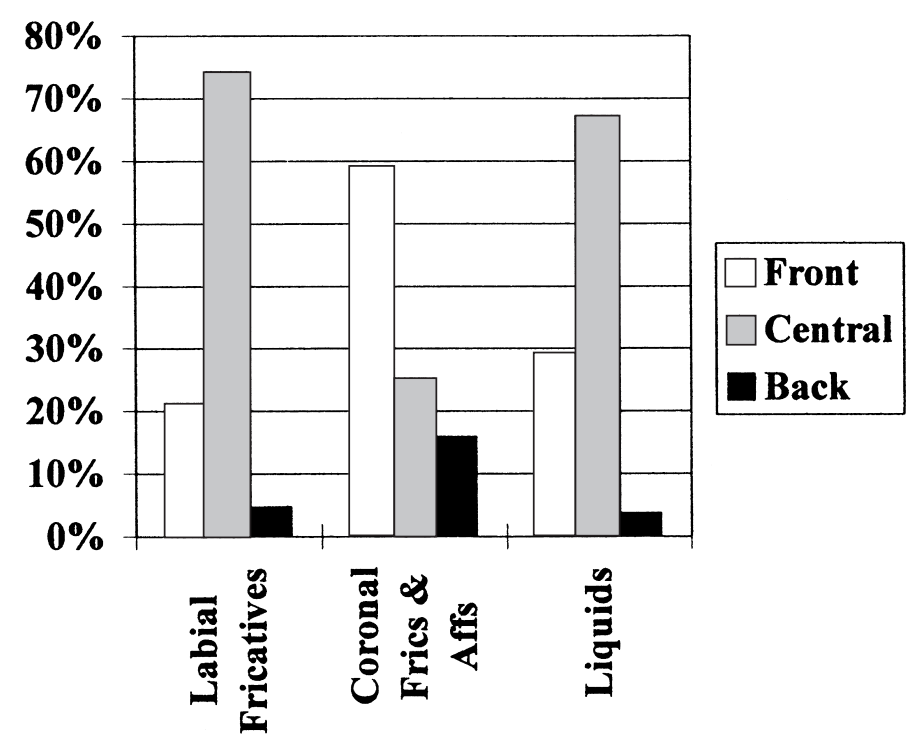

Figure 2. The phonotactic distribution of LDCs as a percentage of total consonant productions for the group average.

Table 3. Number of CV co-occurrences for group $(1,366 C V s)$

\begin{tabular}{lcccc}
\hline \hline & \multicolumn{3}{c}{ LDC manner } & \\
\cline { 2 - 4 } & $\begin{array}{c}\text { Labial } \\
\text { fricatives }\end{array}$ & $\begin{array}{c}\text { Coronal fricatives } \\
\text { and affricates }\end{array}$ & Liquids & $\begin{array}{c}\text { Total } \\
\text { vowels }\end{array}$ \\
\hline Vowel Place & & & & \\
Front & 93 & $\mathbf{1 6 5}$ & 190 & 448 \\
Central & $\mathbf{3 2 0}$ & 79 & $\mathbf{4 4 0}$ & 830 \\
Back & 20 & 44 & 24 & 88 \\
Total LDCs & 433 & 279 & 654 & 1,366 \\
\hline \hline
\end{tabular}

Note: Most frequent consonant-vowel combinations by manner are shown in boldface.

$25)=14.37, p<.001$, for $\mathrm{N} ;(2, N=200)=20.43, p<.001$, for $\mathrm{R}$; liquids $-(2$, $N=162)=35.64, p<.001$, for $\mathrm{C} ;(2, N=42)=14.17, p<.001$, for $\mathrm{N} ;(2, N=$ $159)=1.48, p>.05$, for P; $(2, N=243)=114.27, p<.001$, for R. All CV cooccurrence trends between labial fricatives and central vowels, coronal fricatives and affricates and front vowels, and liquids and central vowels were significant. An additional co-occurrence trend between coronal fricatives and affricates and back vowels was unexpected. However, it should be borne in mind that only $6 \%$ of all vowels were back vowels. 
Gildersleeve-Neumann et al.: Late-developing consonants in babbling

\section{Intersyllabic patterns}

Variegated disyllabic productions containing an LDC were relatively frequent from the onset of canonical babbling in all four infants. Fricatives and affricates occurred in reduplicated disyllabic strings $53 \%$ of the time and in variegated strings $47 \%$ of the time. Liquids occurred in reduplicated strings $42 \%$ of the time and in variegated strings $58 \%$ of the time.

The frequency with which particular liquids, fricatives, or affricates occurred in reduplicated strings was compared to the number of reduplicated strings expected by chance, based on the percentages of the LDCs in the total consonant corpus. Chi-square analyses were conducted on liquids and on fricatives and affricates for each infant. Chi-square results were as follows: fricatives and affricates $-(1, N=12)=0.88, p>.05$, for $\mathrm{C} ;(1, N=25)=122.43, p<.001$, for $\mathrm{N}$; $(1, N=84)=1014.73, p<.001$, for $\mathrm{P} ;(1, N=199)=24.21, p<.001$, for R; liquids $-(1, N=48)=77.45, p<.001$, for C; $(1, N=24)=1831.79, p<.001$, for $\mathrm{N} ;(1, N=24)=0.91, p>.05$, for P; $(1, N=144)=46.16, p<.001$, for $\mathrm{R}$. The number of reduplicated strings containing an LDC was greater than the number expected in six of eight potential environments, as shown in Table 4. The two exceptions were percentage of reduplicated fricative and affricates for $\mathrm{C}$ and percentage of reduplicated liquid utterances for $\mathrm{P}$, both of which approximated expected values. Table 5 shows percentage of reduplicated CVCV strings containing an LDC for each infant.

Changes in variegated strings were analyzed to determine if the changes were more often changes in the vertical than in the horizontal dimension, as predicted. Table 6 shows the frequencies of variegated vowel combinations involving height, front/back, and both height and front/back axes of production. The expected vowel combinations within a CVCV utterance were divided into two possible combinations: change in the front/back axis and change in vowel height. These expected frequencies were then compared to the actual frequencies of these vowel combinations (see in Table 7). The number of observed vowel changes was divided by the number expected for each type of change, with any result greater than 1.0 suggesting a greater than chance occurrence. Variegated vowel combinations demonstrating change in both vowel height and the front/ back axis were excluded from this analysis, as there was no prediction at this point regarding their frequency of occurrence.

As predicted, vowel height changes predominated over front/back changes in all four subjects - significantly so in two infants ( $N$ and $\mathrm{R})$. The chi-square analysis results were as follows: $(1, N=19)=0.05, p>.05$, for $\mathrm{C} ;(1, N=17)$ $=13.24, p<.001$, for $\mathrm{N} ;(1, N=17)=2.88, p>.05$ for $\mathrm{P} ;(1, N=48)=5.33$, $p<.05$, for $\mathrm{R}$.

Of the 223 instances of consonant variegation, all but eight involved a pairing of an LDC with an EDC. This distribution is a near-chance expectation based on the relative frequencies of EDCs and LDCs in the overall corpus. The pairs with one EDC and one LDC do not allow an analysis of the relative frequency of manner and place change involving LDCs as they all involve a manner change (i.e., the EDCs are stops and nasals and glides, whereas the LDCs are fricatives, affricates, and liquids). There were only eight pairs in which both 


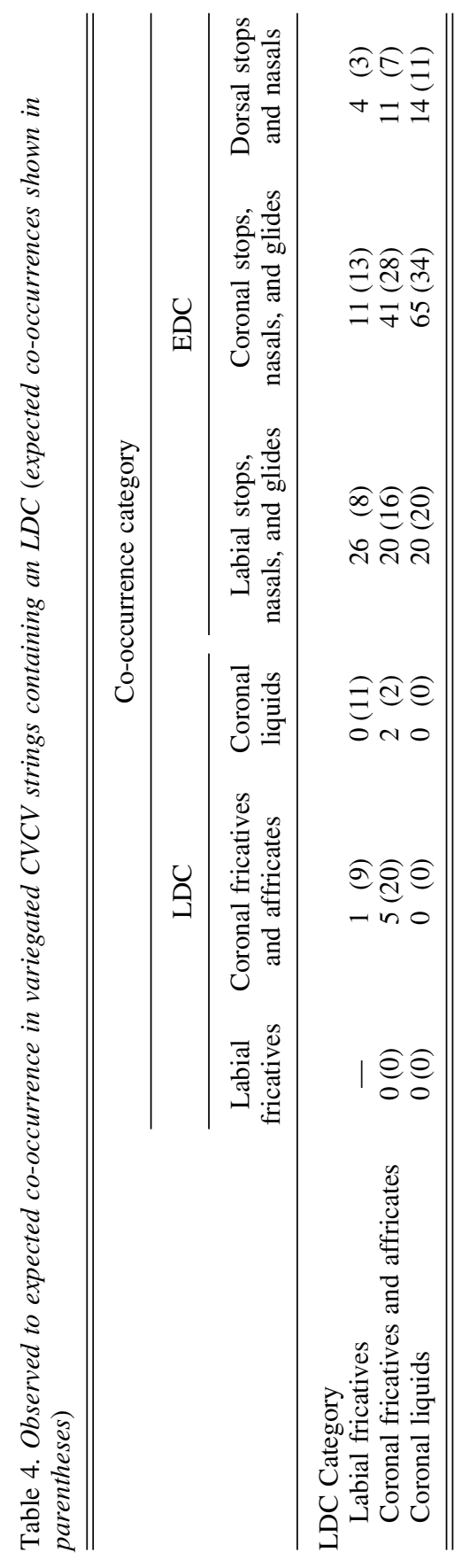


Gildersleeve-Neumann et al.: Late-developing consonants in babbling

Table 5. Percentage of reduplicated CVCV strings containing LDCs (total number of $C V C V$ strings containing a particular LDC shown in parentheses)

\begin{tabular}{lrcccc}
\hline \hline & $\mathrm{C}$ & $\mathrm{N}$ & $\mathrm{P}$ & $\mathrm{R}$ & Total \\
\hline Fricatives and affricates & $0 \%(12)$ & $36 \%(25)$ & $58 \%(24)$ & $58 \%(199)$ & $53 \%(260)$ \\
Liquids & $48 \%(48)$ & $51 \%(45)$ & $61 \%(84)$ & $26 \%(144)$ & $42 \%(321)$ \\
\hline \hline
\end{tabular}

Table 6. Type of vowel variegation occurrences in variegated $C V C V$ strings

\begin{tabular}{lrrrrc}
\hline \hline & $\mathrm{C}$ & $\mathrm{N}$ & $\mathrm{P}$ & $\mathrm{R}$ & Total \\
\hline Front/back & 9 & 1 & 5 & 16 & 31 \\
Height & 10 & 16 & 12 & 32 & 70 \\
Front/back and height & 14 & 12 & 8 & 42 & 76 \\
\hline \hline
\end{tabular}

Table 7. Ratio of observed to expected vowel height variegation (chance level $=1.0$ )

\begin{tabular}{lcccccc}
\hline \hline & \multicolumn{5}{c}{ Individual subjects } & Group \\
\cline { 2 - 5 } & $\mathrm{C}$ & $\mathrm{N}$ & $\mathrm{P}$ & $\mathrm{R}$ & mean \\
\hline Vowel Change & & & & & \\
Front/back & 0.83 & 0.24 & 0.2 & 0.7 & 0.59 \\
Height & $\mathbf{1 . 1 9}$ & $\mathbf{1 . 4 7}$ & $\mathbf{1 . 8 2}$ & $\mathbf{1 . 3 5}$ & 1.41 \\
Significance* & $n s$ & $* * *$ & $n s$ & $*$ & $* * *$ \\
\hline \hline
\end{tabular}

Note: Ratios greater than expected by chance are shown in boldface.

$* p<.05 ; * * * p<.001$.

consonants were LDCs. Of these, seven pairs involved a manner change, and one pair involved a place change. However, given that about four-fifths of LDCs were coronals, this low rate of place change did not exceed chance expectations.

\section{Position-in-utterance patterns}

To determine whether one position was favored for LDC occurrence, the percentages of LDCs in initial, medial, and final position were calculated. The results of these analyses are shown in Figure 3. Since affricate productions were rare and were found to follow the same patterns as fricatives, they were grouped with the fricatives for this analysis. 
Gildersleeve-Neumann et al.: Late-developing consonants in babbling

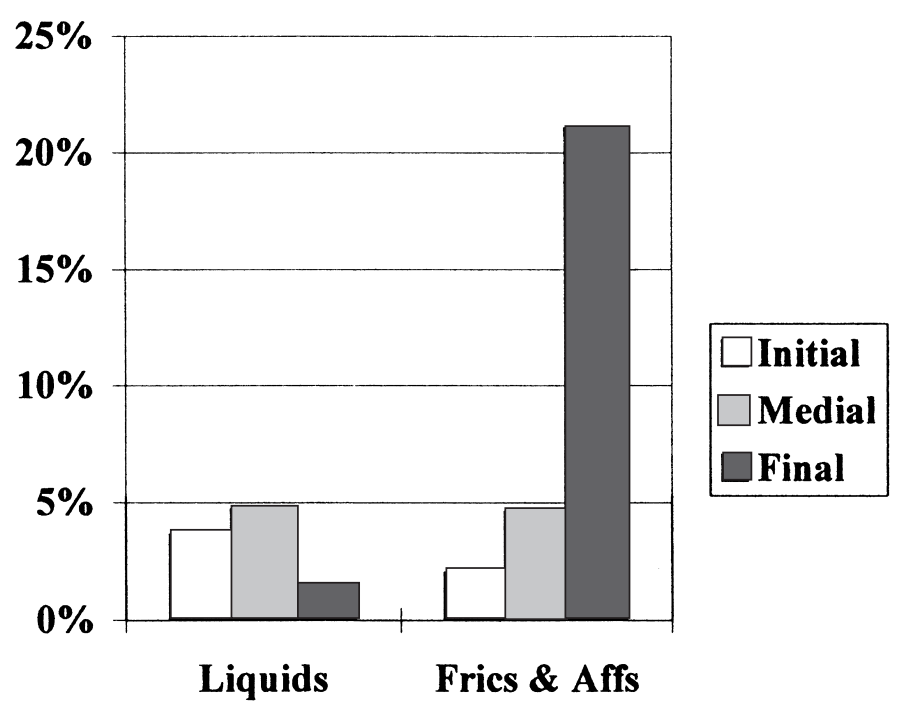

Figure 3. The percentage of CV co-occurrence for LDCs by place and manner of articulation.

Fricatives and affricates were most frequent in final position throughout the period analyzed, as was observed by Redford et al. (1997) who compared final with prefinal consonants (her study included the four infants in this study). In this study, they comprised over $21 \%$ of final consonants, but also showed a slightly larger percentage $(5 \%)$ in medial position than in initial position $(2 \%)$. A preference for final fricatives was observed for all infants.

Liquids comprised a slightly greater percentage of total medial consonant sounds $(5 \%)$ than initial $(4 \%)$ or final $(1.5 \%)$, based on overall consonant productions.

\section{DISCUSSION}

This section summarizes the results regarding the LDC inventories and the effects of the three types of constraints; we focus primarily on the similarities and differences between LDCs and EDCs.

\section{Inventories}

LDCs were present in the phonetic inventories of all four infants from the onset of canonical babbling. Most LDCs were produced in the coronal region. Affricate productions were infrequent throughout the study for all infants.

Previous studies have suggested that liquids are rare in the phonetic inventories of infants at the onset of first words. Thus, their relatively large frequency (4\% of all consonants) in early canonical babbling was unexpected, though still much lower than adult frequencies. The frequency of fricatives and affricates 
reflected frequencies previously reported; however, there were more fricatives and affricates produced than are typically reported in first words.

While individual subjects generally followed group trends, a few individual differences were noted. The percentage of LDCs in individual infant inventories varied considerably. R produced more LDCs from the onset of canonical babbling and produced the greatest variety of LDCs. P differed from the other three infants in a number of ways: the emergence of meaningful speech occurred later, and he demonstrated a more limited output, lower fricative production, and higher $\mathrm{CV}$ dependence than the other infants. The other three infants demonstrated highly similar patterns across the study.

\section{Intrasyllabic CV co-occurrence patterns}

Fricative and affricate LDCs showed similar CV co-occurrence patterns to EDCs. Coronal fricatives and affricates co-occurred with front vowels and labial fricatives co-occurred with central vowels with a frequency significantly greater than expected by chance. Liquids, in contrast, were found to differ significantly from other coronal consonants in their co-occurrence patterns, co-occurring most frequently with central vowels.

What might be the explanation for the unexpected co-occurrence of liquids with central vowels? In adults, both $/ \mathrm{I} /$ and $/ \mathrm{I} / \mathrm{t}$ tend to co-occur preferentially with front vowels. It may be that the infants in this study were producing these sounds in a different way than adults, but the transcribers accepted them as instances of English / $/$ / and / $/ \mathrm{x}$. It is possible that the place of articulation of early liquid productions by infants is more central than it is in adult productions. Further acoustical studies are necessary to explore this possibility.

\section{Intersyllabic patterns}

When syllables in multisyllabic utterances were analyzed pair by pair, LDCs were found to be like EDCs in an almost equal frequency of pairs with consonant reduplication and variegation. As with EDC reduplication, frequencies of specific CV forms were considerably higher than expected by chance. This finding suggests that the infants had sufficient control over LDCs to produce the same closure repeatedly in successive mandibular cycles. However, examination of the records of individual sessions shows that many of the instances of reduplication occurred on relatively isolated occasions of brief but intensive use. For example, during session 31, R produced /v/ 42 times, only five of which were not in reduplicated babble. During the following session, she produced six instances of /v/, all in reduplicated strings and then never produced /v/ again. This pattern of sporadic bursts of LDCs contrasts with the pattern of production of EDCs, which occurred in reduplicative episodes more consistently from session to session for all infants. Thus, the beyond-chance frequencies of LDC reduplication may only indicate a transient production of these sounds rather than any control over successive movement. While consonant manner variegation did not exceed place variegation for LDCs, most vowel variegation in LDC environments was in height, as was the case in EDC environments. 


\section{Position-in-utterance patterns}

Initial and medial position were preferred for liquid LDCs. These findings provide some support for previous findings on the phonotactic distribution of liquids in first words and babbling, which have suggested that liquids are most likely to occur prevocalically. However, liquids were not very frequent in any position.

Fricatives were most frequently produced in final position. These findings are consistent with the findings of other research that fricatives are more frequent in final position in babbling and first words. Although affricates were very limited in frequency, they showed phonotactic constraints similar to fricatives.

As was pointed out earlier, the tendency of fricatives to be in final position may not have implications specific to fricatives, but may instead be part of a general pattern of phonetic effects that follows from an utterance-terminal decrease in energy delivered to the entire speech production apparatus (Redford et al., 1997). There may be three components to this pattern. The terminal vocal intensity reduction observed during babbling by Davis, MacNeilage, and colleagues (Davis et al., in press) may result from a terminal decrease in respiratory drive, resulting in a decrease in subglottal pressure. Finnegan, Luschei, and Hoffman (1998) found that subglottal pressure is the primary determinant of both phasic and tonic changes in vocal intensity in adults. Terminal decreases in fundamental frequency and increases in final voiceless consonants may result from a combination of reduced respiratory drive and reduced vocal fold tension. The increase in fricatives may result from a terminal decrease in amplitude of articulatory displacement in the mandible, perhaps together with the lips in the case of labial fricatives or with the tongue in the case of coronal fricatives and liquids. This decrease in the frequency with which the vocal tract reaches its modal position of complete closure during the utterance-final elevation phase of the mandibular cycle could increase the frequency with which a transcriber observes frication. In the case of nasals, a terminal reduction of the input to the levator palatini muscle, which is responsible for velic closure during normal oral sound production, may increase the number of occasions in which the velum is partially open for final consonants, giving rise to the impression of nasality. The importance of the hypothesis that a single phenomenon underlies a large family of utterance-final effects in babbling is enhanced by the fact that many of these effects are widespread in languages, and some of them, such as final devoicing and frication, even become incorporated in word patterns (e.g., final devoicing in German), whether or not the word is the final part of an utterance (Hock, 1986).

\section{GENERAL DISCUSSION}

What are the implications of this work for the general nature of LDCs in babbling? This question can be addressed by comparing LDCs with EDCs as they reflect patterns of production. The fact that fricatives were found to be most similar to EDCs in their susceptibility to $\mathrm{CV}$ co-occurrence patterns - labials 
with central vowels and coronals with front vowels - is additional evidence for the primacy of frame dominance in babbling. Even the liquids, which showed a co-occurrence pattern not predicted from the frame dominance, showed the characteristic interdependencies, providing further support for the conclusion that there is a lack of segmental independence in the babbling stage. The preferences for the favored co-occurrence patterns tended to be higher for LDCs than EDCs, suggesting that the former were somewhat more contextually constrained than the latter. This result is consistent with the claim that these sounds are more difficult to produce. However, given the comparatively small databases available for LDCs in babbling corpora, this particular result should be replicated before it is emphasized as a general phenomenon.

LDCs were similar to EDCs at the utterance level in two ways. Consonants participated at beyond-chance levels in reduplication. Vowels were more subject to variegation in the vertical dimension than in the horizontal dimension (Davis \& MacNeilage, 1995). However, participation in reduplication, although beyond chance, seemed to be different than it was for EDCs, in that it was not consistently observed across sessions. Thus, the production of LDCs might be, in part, a result of occasional temporary phases in which the usual full closure associated with the mandibular cycle is not consistently achieved. The tendency of LDCs, like EDCs, to have more variation in the vertical dimension in adjacent vowels is further evidence for the claim, arising from the frame dominance concept, that intersyllabic variation in babbling may result primarily from variation in the amplitude of mandibular oscillation. It is possible that much of this variation is adventitious rather than under intentional control.

At the position-in-utterance level, it has been suggested that the only distinctive trend for LDC (i.e., toward a higher frequency of final fricatives) may have little to do with the specifics of producing an LDC. The very low frequencies of fricative production elsewhere in the utterance and the low frequencies of liquid production in all positions contribute further to the impression that these sounds are not yet under consistent control.

There seem to be two possible implications of the findings of this study for clinical aspects of the acquisition of LDCs. First, practitioners should take into account the positional effects on fricative occurrence when planning and evaluating remedial regimes. Second, fricatives may be even more susceptible to the usual CV co-occurrence constraints than EDCs, suggesting that assessment should include vowel phonetic context information in order to plan remedial procedures.

\section{CONCLUSION}

Two major conclusions can be drawn from this study of the frequency and distribution of LDCs in babbling. First, these results provide further support for frame dominance as a generalized conception of the nature of babbling: LDCs were, for the most part, subject to the same constraints on intersyllabic variation and intrasyllabic CV co-occurrence as EDCs. Second, the paucity of evidence indicating that LDCs are subject to unique contextual effects suggests that their low frequencies are primarily a result of intrasegmental motor control difficulties that apply regardless of context. 
Gildersleeve-Neumann et al.: Late-developing consonants in babbling

\section{APPENDIX}

Number of LDCs and percentage of LDCs in infants' total consonant inventories

\begin{tabular}{|c|c|c|c|c|c|c|c|c|}
\hline & \multicolumn{2}{|c|}{$\mathrm{C}$} & \multicolumn{2}{|c|}{$\mathrm{N}$} & \multicolumn{2}{|c|}{$\mathrm{P}$} & \multicolumn{2}{|c|}{$\mathrm{R}$} \\
\hline & \# & $\%$ & \# & $\%$ & \# & $\%$ & \# & $\%$ \\
\hline Liquids & 170 & $3.0 \%$ & 44 & $1.3 \%$ & 165 & $8.0 \%$ & 270 & $5.5 \%$ \\
\hline Affricates & 14 & $0.2 \%$ & 5 & $0.1 \%$ & 5 & $0.2 \%$ & 70 & $1.4 \%$ \\
\hline Fricatives & 51 & $0.9 \%$ & 49 & $1.4 \%$ & 58 & $2.8 \%$ & 529 & $10.7 \%$ \\
\hline Total LDCs & 235 & $4.1 \%$ & 98 & $2.8 \%$ & 228 & $11.0 \%$ & 869 & $17.6 \%$ \\
\hline
\end{tabular}

\section{ACKNOWLEDGMENTS}

The data collection and transcription phases of this work were supported by an NICHD grant, Number R01-HD27733-04. The research for this work and preparation of the manuscript were supported by a U.S. Department of Education Award, Number H029D50040-96.

\section{REFERENCES}

Boysson-Bardies, d. B. (1993). Ontogeny of language-specific syllabic productions. In d. B. Boysson-Bardies (Ed.), Developmental neurocognition: Speech and face processing in the first year of life (pp. 353-363). Dordrecht: Kluwer.

Braine, M. D. S. (1974). On what might constitute learnable phonology. Language, 50, 270-299.

Bush, C. N., Edwards, M. L., Luckau, J. M., Stoel, C. M., Macken, M. A., \& Peterson, J. D. (1973). On specifying a system for transcribing consonants in child language. Stanford, CA: Stanford University, Stanford Child Language Project.

Davis, B. L., \& MacNeilage, P. E. (1990). Acquisition of correct vowel production: A quantitative case study. Journal of Speech and Hearing Research, 33, 16-27.

(1994). Organization of babbling: A case study. Language and Speech, 37, 341-355.

(1995). The articulatory basis of babbling. Journal of Speech and Hearing Research, 38, 1199_ 1211.

Davis, B. L., MacNeilage, P. F., \& Matyear, C. L. (2000). Acquisition of serial complexity in speech production: Phonetic patterns in first words. Manuscript submitted for publication.

Davis, B. L., MacNeilage, P. F., Matyear, C. L., \& Powell, J. (in press). Prosodic correlates of stress in babbling: An acoustical study. Child Development.

Finnegan, E., Luschei, E., \& Hoffman, H. (1998). Modulations of respiratory and laryngeal activity associated with changes in vocal intensity. National Center for Voice and Speech Status and Progress Report, 12, 11-22.

Fudge, E. C. (1969). Syllables. Journal of Linguistics, 5, 253-286.

Guidabaldi, J., Newborg, J., Stock, J. R., Svinicki, J., \& Wneck, L. (1984). Battelle Developmental Inventory. Allen, TX: DLM Teaching Resources.

Hock, H. H. (1986). Principles of historical linguistics. Berlin: de Gruyter.

Hodge, M. M. (1989). A comparison of spectral temporal measures across speaker age: Implications for an acoustical characterization of speech acquisition. Unpublished dissertation, University of Wisconsin, Madison.

Jakobson, R. (1968). Child language, asphasic and phonological universals (A. Keiler, Trans.). The Hague: Mouton. (Original work published 1941)

Kent, R. D., \& Bauer, H. R. (1985). Vocalizations of one-year olds. Journal of Child Language, $12,491-526$ 
Kent, R. D., \& Murray, A. (1982). Acoustic features of infant vocalic utterances at 3, 6 and 9 months. Journal of the Acoustical Society of America, 72, 353-365.

Kent, R. D., \& Read, C. (1992). The acoustic analysis of speech. San Diego, CA: Singular Publishing.

Kuhl, P. K. (1987). Perception of speech and sound in early infancy. In P. Salapatek \& L. B. Cohen (Eds.), Handbook of infant perception (Vol. 2, pp. 275-382). New York: Academic.

Levitt, A. G., \& Wang, Q. (1991). Evidence for language-specific rhythmic influences in the reduplicative babbling of French- and English-learning infants. Language and Speech, 34, 235-249.

Locke, J. (1983). Phonological acquisition and change. New York: Academic.

MacNeilage, P. F., \& Davis, B. L. (1990). Acquisition of speech production: The achievement of segmental independence. In W. J. Hardcastle \& A. Marchal (Eds.), Speech production and speech modelling (pp. 55-66). Dordrecht: Kluwer.

(1996, June). From babbling to first words: Phonetic patterns. Paper presented at the First ESCA Tutorial and Research Workshop on Speech Production Modeling, Fourth Speech Production Seminar, Autrans, France.

MacNeilage, P. F., Davis, B. L., Kinney, A., \& Matyear, C. L. (1999). Origin of speech output complexity in infants and in language. Psychological Science, 10, 459-460.

Maddieson, I. (1984). Patterns of sounds. Cambridge: Cambridge University Press.

Matyear, C., MacNeilage, P. F., \& Davis, B. L. (1997). Nasalization of vowels in nasal environments in babbling: Evidence for frame dominance. Phonetica, 55, 1-17.

Menn, L. (1983). Development of articulatory, phonetic and phonological capabilities. In B. Butterworth (Ed.), Language production (Vol. 2). London: Academic.

Mitchell, P., \& Kent, R. (1990). Phonetic variation in multisyllabic babbling. Journal of Child Language, 17, 247-265.

Munhall, K. G., \& Jones, J. A. (1998). Articulatory evidence for syllable structure. Behavioral and Brain Sciences, 21, 524-525.

Nittrouer, S. (1993). The emergence of mature gestural patterns is not uniform: Evidence from an acoustic study. Journal of Speech and Hearing Research, 36, 959-972.

Oller, D. K. (1980). The emergence of the sounds of speech in infancy. In G. H. Yeni-Komshian, J. F. Kavanagh, \& C. A. Ferguson (Eds.), Child phonology: Vol. 1. Production (pp. 21-35). New York: Academic.

(1990). Logical International Phonetics Program (LIPP) (Version 1.4) [computer software]. Miami, FL: Intelligent Hearing Systems.

Oller, D. K., \& Eilers, R. E. (1982). Similarity of babbling in Spanish- and English-learning babies. Journal of Child Language, 9, 565-577.

Oller, D. K., \& Steffens, M. L. (1993). Syllables and segments in infant vocalizations and young child speech. In M. Yavas (Ed.), First and second language phonology. San Diego, CA: Singular Publishing.

Oller, D. K., Wieman, L. A., Doyle, W. J., \& Ross, C. (1976). Infant babbling and speech. Journal of Child Language, 3, 1-11.

Quinlan, P. T. (1992). Oxford Psycholinguistic Database. Oxford: Oxford University Press.

Redford, M. A., MacNeilage, P. F., \& Davis, B. L. (1997). Production constraints on utterance-final consonant characteristics in babbling. Phonetica, 54, 172-186.

Sander, E. K. (1972). When are speech sounds learned? Journal of Speech and Hearing Disorders, $37,55-63$.

Smith, B. L., Brown-Sweeney, S., \& Stoel-Gammon, C. (1989). A quantitative analysis of reduplicated and variegated babbling. First Language, 9, 175-190.

Stark, R. E. (1980). Stages of speech development in the first year of life. In G. H. Yeni-Komshian, J. Kavanagh, \& C. A. Ferguson (Eds.), Child phonology: Vol. 1. Production (pp. 73-91). New York: Academic.

Stoel-Gammon, C. (1983). Constraints on consonant-vowel sequences in early words. Journal of Child Language, 10, 455-457.

Stoel-Gammon, C., \& Dunn, J. (1985). Normal phonological development. In C. Stoel-Gammon \& J. Dunn (Eds.), Normal and disordered phonology in children (pp. 15-46). Baltimore, MD: University Park Press.

Sussman, H. M., Duder, C., Dalston, E., \& Cacciatore, A. (1999). An acoustic analysis of the 
Gildersleeve-Neumann et al.: Late-developing consonants in babbling

development of CV coarticulation: A case study. Journal of Speech and Hearing Research, 42, 1080-1096.

Sussman, H. M., Minifie, F. D., Buder, E. H., Stoel-Gammon, C., \& Smith, J. (1996). Consonantvowel interdependencies in babbling and early words: Preliminary examination of a locus equation approach. Journal of Speech and Hearing Research, 39, 424-443.

Tyler, A. A., \& Langsdale, T. E. (1996). Consonant-vowel interactions in early phonological development. First Language, 16, 159-191.

Vihman, M. M. (1992). Early syllables and the construction of phonology. In C. A. Ferguson, L. Menn, \& C. Stoel-Gammon (Eds.), Phonological development: Models, research, implications (pp. 393-421). Timonium, MD: York Press.

(1996). Phonological development: The origins of language in the child. Cambridge, MA: Blackwell.

Werker, J. F., \& Tees, R. C. (1984). Cross-language speech perception: Evidence for perceptual reorganization during the first year of life. Infant Behavior and Development, 7, 49-63.

Zlatic, L., MacNeilage, P. F., Matyear, C. L., \& Davis, B. L. (1997). Babbling of twins in a bilingual environment. Applied Psycholinguistics, 18, 453-469. 